JKEP

Vol 6, No 1 (2021)

ISSN: 2338-9095 (Print)

ISSN: 2338-9109 (online)

\title{
Hubungan Tingkat Spiritual dan Religiusitas dengan Tekanan Darah pada Lansia Hipertensi
}

\author{
Anisa Kirnawati ${ }^{1}$, Latifa Aini Susumaningrum ${ }^{1}$, Hanny Rasni ${ }^{1}$, Tantut Susanto ${ }^{1}$, Diana \\ Kholida $^{2}$ \\ Fakultas Keperawatan, Universitas Jember \\ Unit Pelayanan Teknis Pelayanan Sosial Tresna Werdha (UPT PSTW), Banyuwangi \\ email: tantut_s.psik@unej.ac.id
}

\author{
Artikel history \\ Dikirim, Jan $30^{\text {th }}, 2020$ \\ Ditinjau, April $21^{\text {th }}, 2021$ \\ Diterima, May $5^{\text {th }}, 2021$
}

\begin{abstract}
The aging process which happens in elder people has effects on blood pressure. The well maintenance of blood pressure will impact on elder people's daily activities, included in increasing spirituality. This is the one factor which can control over blood pressure. This research uses cross sectional design with purposive sampling method which had been implemented for 70 elder people and got 33 respondents. Data were collected by giving questionnaire such as elder people charactheristic, Daily Spiritual Experimental Scale (DSES) and Sphygnomanometer used to measure blood pressure. Chi-Square Test by 0,05 significance values is examined as data analysis. The result indicates that the average value of spirituality level is Md $39 \pm 36-47,5$ and the average value of blood pressure level is 160,52 systole and 97,09 diastole. Thus, the results also reveals relationship betwen spirituality level and blood pressure (p value 0,002). This study significance shows that the higher level of spirituality is, the easily elder people manage blood pressure. Therefore, elder people living in nursing home should increase the spirituality level or their religion to control blood pressure.
\end{abstract}

Keywords: Spiritual; religiosity; blood pressure; elderly hypertension

\begin{abstract}
ABSTRAK
Proses penuaan yang terjadi pada lansia berpengaruh terhadap peningkatan tekanan darah. pemeliharaan yang baik akan berpengaruh pada aktivitas harian lansia, termasuk dengan meningkatkan spiritualitas. Spiritual merupakan salah satu faktor yang bisa mengandalikan tekanan darah. Penelitian ini menggunakan desain cross sectional dengan metode purposive sampling dilakukan pada 70 lansia dan didapatkan 33 responden. Pengambilan data dilakukan dengan membagikan kuisioner karakteristik lansia, kuisioner kuesioner Daily Spiritual Experimental Scale (DSES) dan Sphygnomanometer digunakan untuk mengukur tekanan darah. Analisis data menggunakan uji Chi-Square
\end{abstract}


dengan nilai signifikansi 0,05 . Hasil penelitian menunjukkan nilai rerata tingkat spiritual Md $39 \pm 36-47,5$ dan rerata tekanan darah sistole 160,52, diastole 97,09. Terdapat hubungan yang signifikan antara tingkat spiritual dengan tekanan darah ( $p$ value $=0,002$ ). Hasil ini memiliki makna semakin tinggi tingkat spiritual semakin bisa lansia dalam mengontrol tekanan darah. Oleh karena itu, lansia di Panti Werdha Banyuwangi harus meningkatkan spiritual untuk mempertahankan tekanan darah mereka.

Kata kunci: Spiritual; tekanan darah; lansia ; hipertensi

\section{PENDAHULUAN}

Menua merupakan proses terjadinya perubahan pada lansia, dimana seseorang akan rentan mengalami sakit (Susanto dkk., 2019). Susenas (2016) menyebutkan jumlah lansia pada tahun mencapai 22,4 juta jiwa atau $8,69 \%$ dengan penyakit terbanyak hipertensi berjumlah 57,6\% (Riskesdas, 2018). Hipertensi merupakan keadaan tekanan sistolik dengan $\geq 140 \mathrm{mmHg}$ dan tekanan diastolik $\geq 90 \mathrm{mmHg}$ (Almarwah, 2017). Hal ini telah disepakati bahwa hasil, pengukuran,menunjukkan

tekanan,darah,sistolik dan tekanan darah diastolik $\geq 140 / 90 \mathrm{mmHg}$ (WHO, 2015). Permasalahan penyakit kronis lansia beriringan dengan masalah psikis yang terganggu, timbul rasa cemas, takut, kekhawatiran dengan penyakit yang dimiliki. Berbagai macam terapi farmakologi dan non farmakologi diterapkan dalam mengurangi hipertensi. Salah satu terapi komplementer yang dapat digunakan dalam mengurangi permasalahan ini adalah dengan meningkatkan spiritual (Munawara, 2017).

Peningkatan spiritual dapat digunakan untuk mengurangi stress, tekanan, depresi yang bisa menyebabkan kenaikan tekanan darah (Lucchese dan Koenig, 2013). Seseorang yang memiliki spiritualitas yang kuat akan merasakan ketenangan, hal ini yang akan berdampak terhadap tekanan darah seseorang (Mayasari, 2014). Spiritual merupakan motivasi dalam diri yang bisa meyakinkan sesorang dlam memberikan makna hidup sumber kekuatan, serta membantu seseorang untuk memaknai tujuan hidupnya dengan lebih luas (Gómez Palencia dkk., 2016). Spiritual terdiri atas dimensi vertikal dan dimensi horisontal. Dimensi vertikal erat hubungannya antara individu dengan Tuhannya yang dapat mengarahkan lansia dalam menjalani kehidupan, sedangkan dimensi horisontal merupakan hubungan individu dengan dirinya sendiri, orang lain dan dengan lingkungan (Stanley dan Beare, 2006). 
Semakin bertambah usia semakin bertambah tingkat spiritual seseorang (Padila, 2013). Spiritual-membantu lansia dalam beradapasi dengan perubahan yang disebabkan-penyakitkronis (Padila, 2013). Spiritual juga digunakan untuk menetralisir hipertensi. Hal ini menunjukkan bahwa lansia membutuhkan spiritual dalam penyembuhan dan pemulihan penyakitnya (Agli dkk., 2015).

Penelitian ini dilaksanakan di UPT PSTW Banyuwangi. Adapun Program pelayanan sosial yang dilaksanakan di dalam panti hampir sama di seluruh wilayah Indonesia. Kegiatan yang dilakukan di UPT PSTW Banyuwangi antara lain keterampilan, bimbingan rohani, hiburan, pemeriksaan kesehatan, dan kerja bakti yang dilakukan secara rutin (Badan Pusat Statistik, 2015). Penelitian ini dianggap penting karena kita dapat mengetahui bagaimana gambaran spiritual dan tingkat religius dengan tekanan darah pada lansia hipertensi. Beberapa penelitian-yangsudah-dilakukan berkaitan dengan spiritual dan religiusitas antara lain penelitian yang dilakukan (Sudaryanto dan Agustin, 2013) dimana hasil penelitiannya menunjukkan bahwa $70 \%$ dari 30 lansia memiliki spiritualitas baik. Penelitian tersebut hanya menunjukkan gambaran spiritual pada lansia yang mengalami hipertensi namun belum menjelaskan keterkaitan antara hipertensi dengan spiritual dan regilius sehingga peneliti tertarik untuk mengkaji bagaimana hubungan tingkat spiritual dan religiusitas terhadap tekanan darah pada lansia hipertensi di UPT PSTW Banyuwangi.

\section{METODE}

Desain. Penelitian, yang digunakan adalah, survei analitik, melalui pendekatan, cross sectional di Unit Pelayanan Teknis Pelayanan Sosial Banyuwangi,Jawa Timur. Proses pengambilan data dilakukan pada bulan Desember 2019. Peneliti melakukan analisis hubungan tingkat spiritual dengan tekanan darah pada lansia hipertensi. Populasi dalam penelitian ini adalah seluruh lansia di UPT PSTW Banyuwangi yang berjumlah 70 lansia. Teknik pengambilan responden menggunakan purposive sampling dengan memperhatikan kriteria inklusi dan ekslusi peneliti. Adapun kriteria inklusi. sebagai, berikut: (1) Lansia yang memiliki umur 60 tahun keatas, (2) memiliki skor MMSE $\geq 21$, (3) Lansia 
hipertensi yang memiliki tekanan sistolik lebih dari atau sama dengan 140 $\mathrm{mmHg}$ dan diastolik lebih dari sama dengan $90 \mathrm{mmHg}$. Kriteria Ekslusi sebagai berikut: 1) Lansia yang mengalami psikotik, 2) Lansia yang tidak mengisi kuisioner hingga selesai.

Peneliti melakukan screening awal melalui pemeriksaan tekanan darah menggunakan alat yang telah dilakukan uji kalibrasi. Peneliti memilah responden yang mengalami hipertensi dan tidak hipertensi. Setelah dilakukan pemeriksaaan tekanan darah pada 70 lansia, didapatkan 47 lansia mengalami hipertensi. Responden yang mengalami hipertensi kemudian diberikan kuisioner Mini Mental Examination (MMSE) untuk melihat status mental lansia. Setelah Proses screening peneliti mendapatkan 33 responden yang termasuk dalam kriteria inklusi penelitian. Peneliti menjelaskan keterlibatan responden sebagai partisipan serta tujuan penelitian. Adapun alur pengambilan sampel penelitian adalah sebagai berikut:

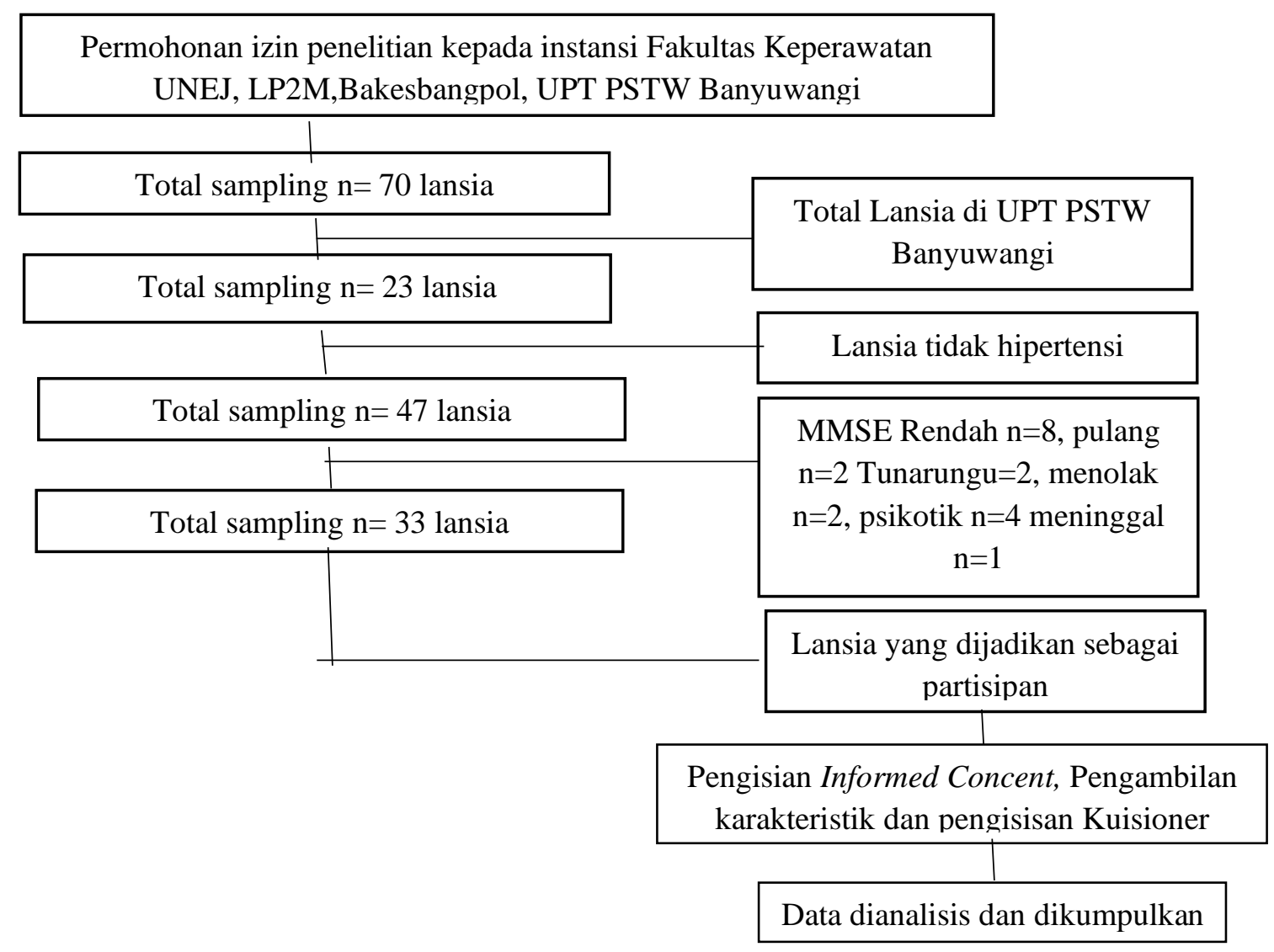

Gambar 1. Alur Pengambilan Sampel Penelitian 
Setelah didapatkan responden yang memenuhi kriteria inklusi peneliti memberikan Informed concent untuk dipahami dan ditandatangani, kuisioner karakteristik lansia, Kuisioner Daily Spiritual Experimental Scale (DSES) untuk mengukur spirual dan kuisioner Skala Religiusitas. Peneliti menjelaskan cara pengisian kuisioner (dalam pengisian dibantu peneliti). Kuisioner karakteristik partisipan berisi data karakteristik usia, jenis kelamin, tingkat pendidikan, status pernikahan. Kuisioner Daily Spiritual Experimental Scale (DSES) digunakan untuk mengetahui tingkat spiritual. Hasil uji validitas kuisioner DSES didapatkan $r$ tabel 0,2104 dan didapatkan $\mathrm{r}$ hitung 0,36 0,83 dengan Cronbach's Alpha sebesar 0,79 (Underwood dan Teresi, 2002). Instrumen ini terdiri dari 16 item pertanyaan yang bersifat positif atau favorable terkait dengan pengalaman spiritual individu, dalam .sehari-hari. kuisioner yang digunakan untuk mengukur tingkat spiritual, tingkat spiritual dikategorikan menjadi tiga yaitu spiritual rendah (15-40), spiritual sedang (41-65), spiritual tinggi (66-90).
Penelitian ini menggunakan analisa univariat dan bivariat, analisa univariat dalam penelitian ini termasuk di dalamnya karakteristik responden, sementara analisa bivariat penelitian ini menggunakan uji statiktik Chi-Square dengan tingakt signifikansi 0,05 dimana dasar penelitian keputusan didapatkan apabila nilai $p$ value < 0,05 maka Ho ditolak dan apabila nilai $p$ value $>0,05$ maka Ho diterima (Sujarweni, 2015). Penelitian ini telah mendapatkan uji etik dari Komite Etik Penelitian Kesehatan (KEPK) di Fakultas Kedokteran Gigi Universitas Jember No. 655/UN25.8/KEPK/DL/2019.

\section{HASIL DAN PEMBAHASAN}

Usia rata-rata lansia di Unit Pelayanan Teknis Pelayanan Sosial Tresna Werdha (UPT PSTW) adalah 69,79 tahun, dengan jumlah lansia perempuan lebih banyak dibandingkan laki-laki yaitu sejumlah $66,7 \%$. Tingkat pendidikan paling banyak adalah sekolah dasar dengan presentase $84,8 \%$. Status pernikahan lansia paling banyak adalah janda atau duda sebanyak 93,9\%. 
Tabel 1. karakteristik lansia di UPT PSTW Banyuwangi ( $n=33$; Desember 2019)

\begin{tabular}{|c|c|c|}
\hline Karakteristik Responden & Mean & SD \\
\hline Usia & 69,79 & 7.167 \\
\hline Karakteristik Responden & \multicolumn{2}{|c|}{$\mathrm{n}(\%)$} \\
\hline \multicolumn{3}{|l|}{ Jenis kelamin } \\
\hline Laki-laki & & \\
\hline Perempuan & & \\
\hline \multicolumn{3}{|l|}{ Pendidikan } \\
\hline Tidak sekolah/tamat SD & & \\
\hline SLTP/sederajat & & \\
\hline SLTA/sederajat & & \\
\hline Akademi/PT & & \\
\hline \multicolumn{3}{|l|}{ Status Pernikahan } \\
\hline \multicolumn{3}{|l|}{ Menikah } \\
\hline Tidak Menikah & & \\
\hline Janda/duda & & \\
\hline
\end{tabular}

Sumber : Data primer, Desember 2019

Seiring bertambahnya usia tekanan darah seseorang akan meningkat (Stanley dan Beare, 2006). Tekanan darah yang meningkat umumnya dianggap sesuatu yang umum terjadi pada lansia (Lee dan Park, 2017; (Susanto dkk., 2019).

Berdasarkan karakteristik usia rata-rata lansia di UPT PSTW Banyuwangi adalah 69,79 tahun dengan standar deviasi 7, 167. Penelitian yang dilakukan Yuldasari (2018) bahwa usia tua rentan mengalami hipertensi. Semakin bertambah usia seseorang elastisitas pembuluh darah juga semakin berkurang dan berakibat arteri dan aorta kehilangan daya untuk menyesuaikan aliran darah (Anggraeni, 2014). Hal ini dapat disimpulkan bahwa usia berhubungan dengan peningkatan tekanan darah, semakin berpotensi mengalami peningkatan tekanan darah.

Pada Tabel 1 karakteristik jenis kelamin menunjukkan bahwa wanita di UPT PSTW Banyuwnagi lebih banyak mengalami kenaikan tekanan darah dibanding laki-laki sebesar $66,7 \%$. Perempuan yang sudah menopause lebih berpotensi terkena hipertensi dikarenakan wanita yang masih produktif masih terlindungi hormon estrogen, hormon ini berfungsi sebagai antioksidan dan bisa melebarkan pembuluh darah jantung sehingga aliran darah lancar dan suplai oksigen menuju jantung tercukupi (Song dkk., 2018). Wanita yang 
menopouse mengalami penurunan daya tahan tubuh sehingga dibutuhkan tubuh yang aktif untuk membantu metabolisme tubuh dalam mengurangi kejadian hipertensi pada lansia (Yulistina dkk., 2017). Dalam hal ini dapat disimpulkan bahwa bahwa hipertensi cenderung dialami perempuan dibandingkan laki-laki.

Selain itu, tingkat pendidikan menunjukkan sebanyak 28 lansia di UPT PSTW Banyuwangi merupakan tamatan Sekolah Dasar (SD) yang beresiko memiliki nilai kognitif yang rendah. Hasil penelitian yang dilakukan (Agustina dan Unar, 2018) didapatkan hasil dari 51,3\% lansia yang memiliki kognitif rendah mengalami hipertensi dengan $p$ value (0,010). Tingkat pendidikan mempengaruhi fungsi kognitif, tingkat pendidikan tamatan Sekolah Dasar (SD) beresiko memiliki nilai kognitif

Tabel 2. Rerata Tingkat Spiritual Lansia di UPT PSTW Banyuwangi

\begin{tabular}{ccccc}
\hline Variabel & $\mathrm{Md} \pm \mathrm{P}(25-75)$ & $\mathrm{t}$ & P value & $95 \%$ CI \\
\hline Tingkat Spiritual & $39 \pm 36-47,5$ & $<0,001$ & 1,000 & $-4,19-4,20$ \\
\hline
\end{tabular}

Hasil penelitian menunjukkan nilai median tingkat spiritual lansia di Panti Werdha Banyuwangi dengan nilai tengah adalah 39 dengan precentil 36 47,5. Berikut merupakan gambaran spiritual pada lansia di Unit Pelayanan yang rendah (Hanifa, 2016). Hal ini dapat disimpulkan bahwa tingkat pendidikan berhubungan dengan hipertensi.

Pada Tabel 1 didapatkan status pernikahan lansia paling banyak adalah janda atau duda sejumlah 93,9\%. Berdasarkan hasil penelitian (Suhartini dkk., 2018) didapatkan hasil bahwa status pernikahan tidak memiliki korelasi dengan risiko terjadinya hipertensi dengan $p$ value 0,434 dimana masing-masing hampir mempunyai proporsi yang sama yaitu status menikah $46,5 \%$ sedangkan janda atau duda sebanyak 50,8\%. Hal ini menunjukkan bahwa status pernikahan antara lansia yang menikah, janda atau duda tidak memiliki hubungan dengan peningkatan tekanan darah pada lansia. 


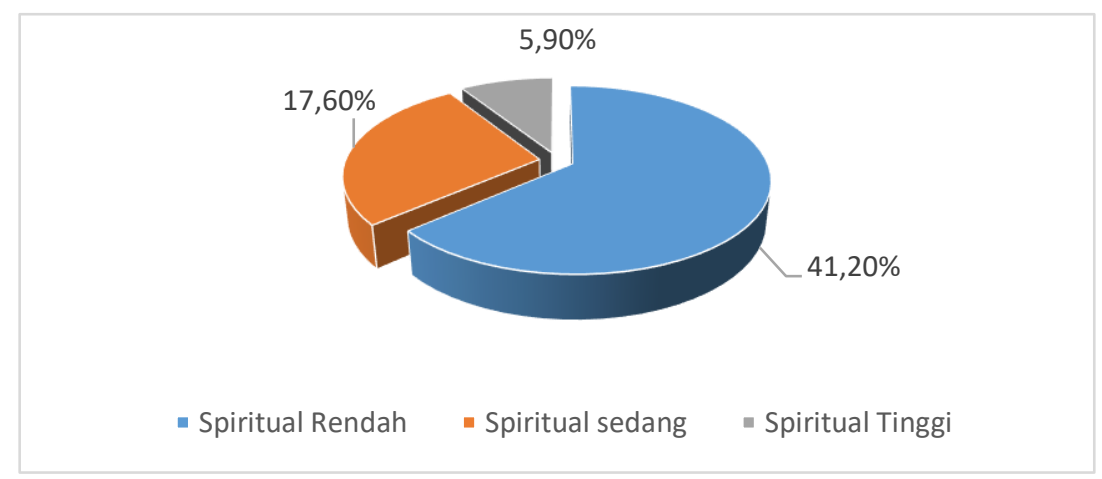

Gambar 1 Distribusi Tingkat Spiritual pada Lansia Hipertensi di Panti Werdha Banyuwangi. Desember $2019(\mathrm{n}=33)$

Gambar 1 menunjukkan bahwa lansia di UPT PSTW Banyuwangi sebanyak $41,2 \%$. Hal ini dapat disimpulkan bahwa UPT PSTW Banyuwangi termasuk kedalam spiritual rendah. Penelitian yang dilakukan (Destarina dkk., 2014) dengan responden lebih banyak dengan total 39 lansia menunjukkan lansia di UPT PSLU memiliki hubungan yang baik dengan sesama. Spiritual merupakan sumber dukungan serta kekuatan bagi lansia dalam mencapai derajat kesehatan dan kesejahteraan hidup (Amir dan Lesmawati, 2016). Hubungan dengan orang individu yang harmonis dapat menjadi motivasi atau dukungan psikologis dan sosial bagi lansia ketika ada permasalahan. Sebaliknya hubungan yang tidak harmonis akan menimbulkan konflik antar lansia yang berakibat kurangnya dukungan spiritual. Hubungan dengan alam seperti mengagumi ciptaan Tuhan yang bisa menciptakan keselarasan jasmani dan rohani, kepedulian terhadap sekitar, sehingga tercipta kedamaian yang terdiri atas keadilan, belas kasih seluruh semesta (Yusuf dkk., 2016). Hubungan dengan Tuhan (dimensi vertikal) merupakan hubungan yang mengatur tentang hubungan seseorang dengan Tuhan (Azizah, 2011) seperti membangun ritual beragama, mensyukuri yang telah diberikan Tuhan, berpuasa, berdoa, sembahyang, seseorang yang dekat dengan Tuhan akan mendapatkan ketenangan, rasa tentram dan nyaman secara batiniah (Yusuf dkk., 2016). Beberapa faktor yang dapat mempengaruhi spiritualitas seseorang, diantaranya tingkat pendidikan, tekanan sosial, pengalaman masa lalu 
(Fitriani, 2016). Adapun faktor yang dapat mempengaruhi spiritual antar lansia di UPT PSTW Banyuwangi disebabkan karena perbedaan kepribadian masing-masing. Peneliti mengasumsikan bahwa lansia di UPT PSTW Banyuwangi memiliki hubungan yang kurang baik dengan sesama, sering bertengkar karena hal kecil, seperti bedak, makanan.

Tabel 4. Distribusi tekanan darah Sistole dan Diastole pada Lansia di UPT PSTW

Banyuwangi

\begin{tabular}{ccccc}
\hline \multicolumn{1}{c}{ Variabel } & Mean $\pm S D$ & Min- Max & $Z$ & $P$ value \\
\hline Tekanan darah sistole & $160,52 \pm 16,600$ & $140-210$ & 0,12 & 0,2 \\
Tekanan darah diastole & $97,09 \pm 9,599$ & $82-118$ & 0,96 & 0,2 \\
\hline Dataprat
\end{tabular}

Data primer peneliti, Desember 2019

Karakteristik responden berdasarkan tekanan darah pada lansia hipertensi di Unit Pelayanan Teknis Pelayanan Sosial Tresna Werdha Banyuwangi, menunjukkan lansia mengalami hipertensi sistole. Seiring bertambahnya usia tekanan darah seseorang akan meningkat (Sujarweni, 2015). Tekanan darah yang meningkat umumnya

Tabel 5. Analisis hubungan tingkat spiritual dengan tekanan darah pada lansia hipertensi di Unit Pelayanan Teknis Pelayanan Sosial Tresna Werdha Banyuwangi

\begin{tabular}{lcccccccc}
\hline \multirow{2}{*}{ Tingkat Spiritual } & \multicolumn{3}{c}{ Tekanan Darah Sistole } & & \multicolumn{2}{c}{ Total } & \multirow{2}{*}{ P } \\
\cline { 2 - 5 } & \multicolumn{2}{c}{ Hipertensi I } & \multicolumn{2}{c}{ Hipertensi II } & & & Value \\
& $\mathrm{f}$ & $\%$ & $\mathrm{f}$ & $\%$ & $\mathrm{f}$ & $\%$ & \\
\hline Spiritual Rendah & 6 & 18 & 15 & 45,5 & 21 & 63,3 & \\
Spiritual Sedang & 9 & 27,3 & 0 & 0,0 & 9 & 27,3 & 0,001 \\
Spiritual Tinggi & 2 & 6,1 & 1 & 3,0 & 3 & 9,1 & \\
\hline Total & $\mathbf{1 7}$ & $\mathbf{5 1 , 5}$ & $\mathbf{1 6}$ & $\mathbf{4 8 , 5}$ & $\mathbf{3 3}$ & $\mathbf{1 0 0}$ &
\end{tabular}

Data primer peneliti, Desember 2019

Tabel 3x2 tidak memenuhi syarat apabila dilakukan uji Chi-Square

dianggap sesuatu yang umum terjadi pada lansia (Susanto dkk., 2019). Semakin bertambah usia seseorang elastisitas pembuluh darah juga semakin berkurang dan berakibat arteri aorta kehilangan daya untuk menyesuaikan aliran darah (Anggraeieni dan Nur, 2014). 


\begin{tabular}{|c|c|c|c|c|c|c|c|c|}
\hline \multirow{3}{*}{ Tingkat Spiritual } & \multicolumn{4}{|c|}{ Tekanan Darah Sistole } & \multirow{2}{*}{\multicolumn{2}{|c|}{ Total }} & \multirow{3}{*}{$\begin{array}{c}\mathrm{P} \\
\text { Value }\end{array}$} & \multirow{3}{*}{ OR } \\
\hline & \multicolumn{2}{|c|}{ Hipertensi I } & \multicolumn{2}{|c|}{ Hipertensi II } & & & & \\
\hline & $f$ & $\%$ & $\mathrm{~F}$ & $\%$ & $\mathrm{f}$ & $\%$ & & \\
\hline Spiritual Rendah & 6 & 28,6 & 15 & 71,4 & 21 & 100 & & \\
\hline Spiritual Sedang & 11 & 91,7 & 1 & 8,3 & 12 & 100 & 0,002 & 27,5 \\
\hline Total & 17 & $\mathbf{5 1 , 5}$ & 16 & $\mathbf{4 8 , 5}$ & 33 & 100 & & \\
\hline
\end{tabular}

Data primer peneliti, Desember 2019

Hasil uji menggunakan Chi-Square didapatkan hasil $p$ value $=0,002$ yang menunjukkan adanya hubungan antara tingkat spiritual dengan tekanan darah pada lansia hipertensi.

Penelitian sebelumnya menjelaskan peran spiritual sebagai presepsi terhadap sakit, di dalam penelitian disebutkan bahwa seseorang yang memiliki tingkat spiritual yang baik akan mampu beradaptasi dengan perubahan fisik karena kerentanan dan permasalahan penyakit yang terjadi pada lansia (Dewi, 2016). Spiritual digunakan dalam meningkatkan kesehatan terutama dalam kesehatan fisik, psikis (Mcsherry, 2004) dalam (El Fath, 2015). Karakteristik Spiritual merupakan tidak tampak, tidak bisa diraba dan bisa mempengaruhi pikiran serta perilaku lansia yang dibangun melalui cinta kasih, agama, keyakinan, rasa memiliki, kekuatan pribadi, interaksi dengan alam (Yusuf, A.H dan, R \& Nihayati, 2016). Terdapat 6 aspek dalam spiritual yaitu pelarian makna hidup, kerohanianmerupakan proses dalam mencari relasi, kerohanian merupakan proses pendekatan diri pada Transender (Tuhan), spiritual mengandung manifestasi seperti cinta, kedamaian, kebijaksanaan, keajaiban, dan seterusnya, spiritualitas mengandung fenometa yang tidak berwujud konsep (Bergunder dkk., 2015). Menurut (Naewbood dan Kantharadusadee, 2012) ketika seseorang dalam keadaan sakit dan stress agama dan spiritual sangat berperan penting dalam mekanisme koping. Penelitian ini sejalan dengan penelitian yang dilakukan oleh (Gholami dkk., 2017) dengan nilai $p$ value $<0,001$ yang menunjukkan adanya keterkaitan antara spiritual dengan kejadian hipertensi yang dialami lansia, dalam penelitian tersebut dijelaskan bahwa peningkatan dalam ketrampilan spiritual dan religiusitas dapat menyebabkan peningkatan yang signifikan dalam kekuatan dan ketahanan kesehatan serta penurunan 
yang signifikan dalam keluhan somatik yang dialami lansia dengan hipertensi (Gholami dkk., 2017). Hasil penelitian sebelumnya didapatkan hasil adanya keterkaitan yang signifikan antara strategi koping spiritual dan religiusitas dengan penurunan risiko terjadinya hipertensi (Cozier dkk., 2018). Keyakinan dengan Transender juga merupakan salah satu faktor yang dapat mempengaruhi tekanan darah (Koenig, 2012). Dalam penelitian ini didapatkan hasil $p$ value dengan nilai $<0,002$. Hal ini sejalan dengan penelitian yang dilakukan (Sherma dan J.W, 2017) dengan nilai $p$ value sebesar 0,000 yang menujukkan adanya hubungan antar religius dengan tekanan darah pada lansia. Agama berfungsi sebagai penyelamat, pemberi pelajaran, pengawasan sosial, dan tranformatif (Hendropuspito, 2001). Hal ini dapat disimpulkan spiritual dapat memberikan kedamaian dan keteguhan dalam diri seseorang, semakin tinggi spiritual seseorang semakin meningkat kesehatan seseorang sesuai dengan fungsinya agama dapat memberikan perubahan ketika seseorang dalam keadaan terpuruk dari sakit maupun stress.

\section{SIMPULAN}

Berdasarkan hasil penelitian yang didapat disimpulkan bahwa tingkat spiritual berhubungan dengan tekanan darah pada lansia hipertensi $\left(X^{2}=9,776\right.$; nilai $p$ value: 0,002). Implikasi Keperawatan yang dapat dilakukan untuk mencegah dan mengurangi kejadian hipertensi di UPT PSTW Banyuwangi, diantaranya upaya promotif dengan memberikan pengetahuan kepada lansia beserta praktiknya, meningkatakan gerakan peduli sekitar seperti kerja bakti, berkebun, perawat memberikan semangat hidup agar lansia merasa hidupnya berguna, upaya preventif terkait komplikasi yang terjadi, dengan meningkatkan spiritual lansia, meningkatkan kegiatan keagamaan, membentuk kelompok dukungan sebaya untuk saling mengingatkan untuk ibadah sesuai agama yang dianut. Menggunakan SEFT Theraphy untuk mengatasi permasalahan fisik, emosi, pikiran dan perasaan supaya lebih tenang dengan mengaktifkan jalur meridian dengan cara ketukan ringan di 9 dan 18 titik meridian tubuh. Peneliti menyarankan agar penelitian selanjutnya mengambil responden lebih banyak dengan melakukan penelitian lebih dari satu 
Panti Werdha. Selain itu, peneliti menyarankan agar penelitian selanjutnya dapat mengkaji lebih dalam terkait faktor-faktor yang dapat mempengaruhi tingkat spiritual dan religiusitas pada lansia beserta efeknya terhadap tekanan darah.

\section{UCAPAN TERIMA KASIH}

1. Almamater Program Studi Sarjana Keperawatan Fakultas Keperawatan, Universitas Jember dan seluruh Bapak/Ibu Dosen yang telah memberikan ilmu serta bimbingannya selama ini;

2. Kelompok Riset Healthy and Wellness of Elderly Studies, Dosen Pembimbing Utama Ns. Latifa, Ns. Hanny, Ns. Fahruddin Kurdi, Ns. Tantut Susanto, Ns.Fahruddin Kurdi yang telah membimbing selama ini;

3. Seluruh responden di UPT PSTW Banyuwangi, Staf TU beserta Karyawan, Perawat yang bekerja dan membantu dalam kelancaran penelitian.

\section{DAFTAR RUJUKAN}

Agli, O., N. Bailly, dan C. Ferrand. 2015. Spirituality and religion in older adults with dementia: a systematic review. International Psychogeriatrics. 27(5):715-725.
Agustina dan A. . Unar. 2018. Hubungan Karakteristik Dengan Kejadian Hipertensi Pada Lansia Di Kabupaten Kaur Provinsi Bengkulu

Amir, Y. dan D. R. Lesmawati. 2016. Religiusitas dan Spiritualitas: Konsep yang Sama atau Berbeda? Jurnal Ilmiah Penelitian Psikologi. 2(2):67-73.

Anggraeieni dan W. Nur. 2014. Pengaruh Terapi Relaksasi Zikir untuk Menurunkan Stress Pada Penderita Hipertensi Esensial. Jurnal Intervensi Psikologi. 6(1):82-85.

Anggraeni. 2014. Hubungan Status Spiritual Lansia Dengan Gaya Hidup Lansia. 7(1)

Azizah, L. 2011. Keperawatan Lanjut Usia. Yogyakarta: Graha Ilmu.

Bergunder, M., G. Levy, R. Razin, H. Spencer-oatey, G. Frazer, T. G. Bough, S. Carman, C. A. Barrio, E. Jane, M. T. Burke, H. Hackney, P. Hudson, J. Miranti, G. A. Watts, L. Epp, G. Greene, T. D. Nguyen, K. R. ega. Sterba, J. L. Burris, S. P. Heiney, M. B. ake. Ruppel, M. E. Ford, J. Zapka, K. J. Zullig, R. M. Ward, T. Horn, P. Speck, M. Sugino, E. D. Hapsari, E. Madyaningrum, F. Haryant, S. Warsini, S. Takada, H. Matsuo, J. Hilbers, A. S. Haynes, J. G. Kivikko, P. Corrigan, B. Schell, B. McCorkle, K. Kidder, S. Hall, S. Beatty, D. I. Al Husseini, H. Care, M. Muldoon, N. King, B. Shabab, A. Mirza, A. Medicine, D. R. Graber, J. A. Johnson, C. F. Musgrave, C. E. Allen, G. J. Allen, M. . Spencer, A. Discrimination, U. S. H. Care, H. R. W. Page, S. Laws, 
S. Hollins, H. Discrimination, K. McKenzie, A. Tuck, dan M. S. Noh. 2015. What is spirituality? a personal exploration. Nursing Management (Harrow, London, England: 1994). 23(6):39-52.

Cozier, Y. C., J. Yu, L. A. Wise, T. J. VanderWeele, T. A. Balboni, M. A. Argentieri, L. Rosenberg, J. R. Palmer, dan A. E. Shields. 2018. Religious And Spiritual Coping and Risk of Incident Hypertension In The Black Women's Health Study. Annals of Behavioral Medicine. 52(12):989-998.

Destarina, V., Agrina, dan Y. I. Dewi. 2014. Gambaran Spiritualitas Lansia Di Panti Sosial Tresna Werdha Khusnul Khotimah Pekanbaru. Jom Psik. 1(2):1-8.

Dewi, S. R. 2016. Spiritualitas dan Persepsi Kesehatan Lansia Dengan Hipertensi Di Wilayah Kerja Puskesmas Mayang Jember. Journal Of Health Science. 6(2):228-237.

El Fath, N. M. D. 2015. Hubungan antara Spiritualitas dengan Penerimaan Orang Tua Pada Orang Tua yang Memiliki Anak Autis

Fitriani, A. 2016. Peran Religiusitas dalam Meningkatkan Psychological Well Being. AlAdyan. 11(1):57-80.
Gholami, M., F. Hafezi, P. Asgari, dan F. Naderi. 2017. Comparison Of The Effectiveness Of Mindfullness And Spirituallity/ Religious Coping Skills On Health Hardness And Somatic Complaints of Elderly With Hypertension. Health Spirituality and Medikal Ethics. 4(3)

Gómez Palencia, I. P., D. C. Banquett, M. C. Quintana, A. L. Villamizar, dan Y. V. Mendoza. 2016. Spirituality and Religiosity In Elderly Adults With Chronic Disease. Investigacion y Educacion En Enfermeria. 34(2):235-242.

Hendropuspito. 2001. Sosiologi Agama. Yogyakarta: Kanisius.

Koenig, H. G. 2012. Religion, Spirituality, and Health: The Research And Clinical Implications. ISRN Psychiatry. 2012:1-33.

Lucchese, F. A. dan H. G. Koenig. 2013. Religião, Espiritualidade E Doença Cardiovascular: Pesquisa, Implicações Clínicas E Oportunidades No Brasil. Brazilian Journal of Cardiovascular Surgery. 28(1):103-128.

Mcsherry, W. 2004. Making Sense of Spirituallity In Nursing and Health Care Practice. London: Jessica Kingsley Publishers.

Munawara, D. W. I. J. 2017. Hubungan Tingkat Religiusitas Terhadap Tekanan Darah Penderita Hipertensi Di Pedukuhan Karang Tengah Gamping Sleman Yogyakarta 
Naewbood, S. dan Kantharadusadee. 2012. The Role of Religion In Relation To Blood Pressure California Thai Population With Hypertension. Journal of Religion and Health. 3(51)

Padila. 2013. Buku Ajar Keperawatan Gerontik. Yogyakarta: Nuha Medika.

Sherma dan L. J.W. 2017. Religiusity And Hypertension Among Older North American Seventh-Day Adventits. HHS Public Access. 55(2):695-708.

Song, L., L. Shen, H. Lie, Z. X, L. Zhang, Y. Liang, dan Y. Wang. 2018. Age Natural Menopause and Hypertension Among Midle-Aged and Older Chinesewoman. Age Of Menopause and Hypertension. 36(3)

Stanley, M. dan P. . Beare. 2006. Buku Ajar Keperawatan Gerontik (Edisi 2). Jakarta: Buku Kedokteran EGC.

Sudaryanto, A. dan Y. N. Agustin. 2013. Di Unit Pelayanan Teknis Panti Sosial Lanjut Usia ( Upt Pslu ) Magetan. 179-183.

Suhartini, T. Ermawati, Z. Hamzah, dan Z. Meilawati. 2018. Profil Tekanan Darah pada Lansia Di Kecamatan Arjasa Kabupaten Jember. Warta Pengabdian. 4:170-176.

Sujarweni, V. 2015. Statistik Untuk Kesehatan Edisi 1. Yogyakarta: Gava Media.

Susanto, T., H. Rasny, L. A. Susumaningrum, R. A. Yunanto, dan K. R. M. Nur. 2019. Prevalence of Hypertension And Predictive
Factors of Self-Efficacy Among Elderly People With Hypertension In Institutional-Based Rehabilitation In Indonesia. Journal of Nursing and Social Sciences Related to Health and Illness. 21(1):14-21.

Underwood, L. G. dan J. A. Teresi. 2002. The Daily Spiritual Experience Scale: Development, Theoretical Description, Reliability, Exploratory Factor Analysis, and Preliminary Construct Validity Using Health-Related Data. Annals of Behavioral Medicine. 24(1):2233.

Yulistina, F., S. . Deliana, dan E. . Rustiana. 2017. Korelasi Asupan Makanan, Stress Dan Aktifitas Fisik d engan Hipertensi Pada Menopause. Unnes Jurnal Public Health. 6(1)

Yusuf, A.H, F. dan H. ., R \& Nihayati. 2016. Buku Ajar Keperawatan Kesehatan Jiwa. Buku Ajar Keperawatan Kesehatan Jiwa. 1366.

Yusuf, A. ., H. Endang, M. Florentia, dan S. Oktavisanti. 2016. Kebutuhan Spiritual: Konsep Dan Aplikasi Dalam Asuhan Keperawatan. Jakarta: Mitra Wacana Medika. 